\title{
A Means of Allocating the MW REQUiREMENT IN AN EleCtriCAl PoWer SYSTEM
}

\author{
Rogobete, M.; Pintilie, I. \& SCUTARU, M.
}

Abstract: The actual power system is controlled by operators using a series of platforms that cover the power GRID demands. The available MW reserves are used in order to reduce the impact of overall power variation, but the human factor has a reduced efficiency when the flow of operations increase. An automatic tool is proposed for assessing the current state of the power grid in terms of MW generation requirements and to select each available reserve. It has a significant impact during transition periods defined by abrupt changes in schedules, pproaching the daytime peak, etc. The application is powered by an inference fuzzy logic module that return a verbose response, easily understandable by the operator, increasing the process efficiency.A set of general standard rules and maneuvers used in current operation, are implemented by the fuzzy logic module. The outputs of the software tool will indicate which reserve to be selected (secondary or tertiary) and in which proportion.

Key words: GRID, power system eficiency, inference fuzzy
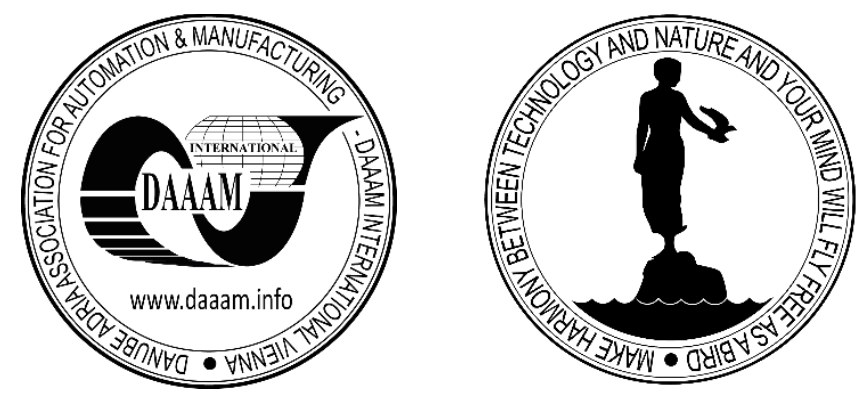

Authors' data: PhD, Dipl.-Ing. Rogobete, M[arius]; PhD Student Pintile, I[oan]; Ing. Scutaru, M[ihai], Alstom GRID Romania, Bld. Dimitrie Cantemir 1, 40231, Bucharest, Romania, marius.rogobete@gmx.de, ioan.pintilie@alstom.com

This Publication has to be referred as: Rogobete, M[arius]; Pintilie, I[oan] \& Scutaru, M[ihai] (2015). A Means of Allocating the MW Requirement in an Electrical Power System, Chapter 25 in DAAAM International Scientific Book 2015, pp.299310, B. Katalinic (Ed.), Published by DAAAM International, ISBN 978-3-902734-051, ISSN 1726-9687, Vienna, Austria

DOI: 10.2507/daaam.scibook.2015.25 


\section{Introduction}

A Power System is usually managed by Dispatching Unit of the Transport System Operator. Several software tools and platforms have been designed to cover the power demand, to optimize the costs, to meet the power schedules and, therefore, to have transparent and unbiased commercial transactions but also, very important, to have high operational security of the power grid.

These operations are focused on activation of the available MW reserves for cost reduction, considering the impact of increasing/decreasing overall generation inside the grid. As the Dispatching Unit concentrates so much information for the best decision of the dispatcher, the operator can take a second option for the final decision, instead the first, best option, e.g. to access a new Secondary reserve even if is scheduled a Tertiary over 1-2 time slots (of 15 minutes). Thus, it is imperious necessary to reduce the number of operations managed by the operator and to offer better decisions for the specific case and finally to have a low level of human factor errors.

An automatic tool is proposed to assess the current state of the power grid, in terms of MW generation requirement. It offers a way of selection for every MW reserve available in the grid. The tool proposed in this paper is designated for dispatcher use and has a significant impact during transition periods defined by abrupt changes in schedules, approaching and leaving the daytime peaks, unexpected generation loss in the system, etc.

This tool is powered by an inference fuzzy logic module capable of returning a verbose response, easily understandable by the operator, thus increasing furthermore the efficiency of this process.

A set of general standard rules, transpositions of the maneuvers used in current operation, are implemented by the fuzzy logic module.

The inputs are obtained from the following applications: the Management Market platform or a similar tool for MW transactions, day-ahead schedules and balancing market, the Automatic Generation Control $(A G C)$ application, the Reserve Monitor $(R M)$ applications or any other tool for computing aggregations on secondary and tertiary reserves, the Load Forecast (LF) applications or other similar tool for MW consumption prognosis.

The Management Market platform will supply the system Scheduled MW Generation values $\boldsymbol{S}(\boldsymbol{t})$ for each time interval.

The Reserve Monitor application will supply Current MW Generation value $\boldsymbol{G}(\boldsymbol{t})$ and the Secondary up $\boldsymbol{S R U}(\boldsymbol{t})$ and down $\boldsymbol{S R D}(\boldsymbol{t})$, and Tertiary up $\boldsymbol{T R U}(\boldsymbol{t})$ and down $\operatorname{TRD}(t)$, MW reserves for each time interval.

The Load Forecast application will supply the MW load value $\boldsymbol{L}(\boldsymbol{t})$, on each time interval and the $A G C$ will supply the Regulation Demand $\boldsymbol{R}(\boldsymbol{t})$, MW value.

Our target is to cover the regulation demand by activating the right reserves at the current time with minimum impact on the network.

Considering the above, the outputs of the proposed tool will indicate which reserve has be selected (secondary or tertiary) and in which proportion. 


\section{Problem definition}

The Regulation Demand is an analog MW value computed as the output of the $P I$ regulator by the $A G C$ application.

The input of the PI regulator is the $A C E$ which varies constantly over time. $A C E$ itself is computed as the difference between scheduled MW interchange and current MW interchange on the $A C$ lines and the frequency deviation in the power system. Considering all the power consumers load in the system going on or off at a certain time, it is usual that frequency value varies constantly within a tolerance band.

Thus $A C E$ and Regulation Demand vary over time within a band of \pm tens, hundreds MW. The Regulation Demand is the $\triangle \mathrm{MW}$ value to be added to current system MW generation in order for the system MW generation to follow the MW load. It can be both positive and negative (increase or decrease system MW generation) and it is a real value.

In this paper we address the potentially harmful Regulation Demand MW values defined as so in comparison with the available Secondary MW Reserve values (Up and Down).

$$
R(t)=K_{p} A C E(t)+K_{i} \int A C E(t) d t, t \in \mathbb{R}
$$

Where $K_{p}$ is the constant proportional gain, $K_{p} \in \mathbb{R}, K_{i}$ is the constant integral gain, $K_{i} \in \mathbb{R}$, and the integration period for the ACE is usually 3600 seconds.

For simulation purpose function (1) can be rewritten as:

$$
R(t)=\operatorname{random}(C), t \in \mathbb{R}, C \in[-S R D, S R U]
$$

Where $S R U$ is Secondary MW Reserve value Up and $S R D$ is Secondary MW Reserve value Down.

The Secondary MW Reserve values (Up and Down) are computed as the sum of the available MW Reserves UP and DOWN of each Regulating Entity of the power system.

Two types of reserves are computed:

- Secondary MW Reserve Up

- Secondary MW Reserve Down.

The Secondary MW Reserves are available at all times and can be accessed really fast, almost instantaneously to cover the Regulation Demand value. Regulation Demand is implemented by all Regulating Entities in the power system participating in AGC and the values of the reserves are recomputed in real time.

The values of the Secondary MW Reserves are taking into consideration the available Regulating Entities in the system, the Current Generation MW value, the total MW generation capacity of the power system, the magnitude of the possible generation deviations, etc. 
Rogobete, M.; Pintilie, I. \& Scutaru, V.: A Means of Allocating the MW Requirem...

Ideally a high value of the Secondary MW Reserves that can cover any type of disturbances is desired but allocating such a high regulating capacity in each time interval is very expensive.

We can propose the following definition intervals for the Secondary MW Reserves:

$$
\begin{gathered}
S R U(t)=C, t \in \mathbb{R}, C \epsilon[0 ; 1000] \\
S R D(t)=C, t \in \mathbb{R}, C \epsilon[-1000 ; 0]
\end{gathered}
$$

Secondary Reserves may be changed technologically only every few seconds, thus equations (2) can be rewritten with $T$ instead $t$ :

$$
\begin{gathered}
S R U(T)=C, C \epsilon[0 ; 1000] \\
S R D(T)=C, C \epsilon[-1000 ; 0]
\end{gathered}
$$

Where:

- $\operatorname{SRU}(T)$ is the Secondary MW Reserve value Up from $T$ to $T+1$

- $S R D(T)$ is the Secondary MW Reserve value Down from $T$ to $T+1$

- $C$ is a constant definable on each time interval of typically a few minutes

- $T=\{1,2, \ldots, 1440\}$ is a breakpoint on each minute of the hour (period starting intervals).

Both $S R U$ and $S R D$ values are recomputed each time interval, to reduce the costs of exploitation of the power grid while maintaining the safety and stability of the system (Eremia, M.; Simon, P. \& Petricica, 2001).

The Tertiary MW Reserves values (Up and Down) are designated to cover possible MW discrepancies that exceed the capability of the Secondary MW Reserves.

Discrepancies are due to unexpected load MW values in the system (increase of consumption due to occurring social events, reduce of consumption due to outages on industrial platforms, etc.) or due to Scheduled MW value that are not respecting their engagement.

Tertiary Regulation is activated by the system operator and it takes up to several minutes (15 minutes typically) to be fully implemented in the power system.

Overall MW generation of the power system is enhanced or reduced with the value activated by the dispatched. Tertiary Regulation is implemented by the same Generation Entities participating at the Schedule MW value. Thus, tertiary regulation is a way of shifting the Schedule MW value Up/Down on a certain time interval for covering discrepancies while keeping Secondary MW Reserves intact.

$$
\begin{gathered}
T R U(T)=C, C \epsilon[0 ; 3000] \\
T R D(T)=C, C \epsilon[-3000 ; 0]
\end{gathered}
$$

Where:

- $\operatorname{TRU}(T)$ is the Tertiary MW Reserve value Up from $T$ to $T+1$

- $T R D(T)$ is Tertiary MW Reserve value Down from $T$ to $T+1$ 
- $C$ is an external value settled on the Market Platform at each 15 minutes of the hour

- $T=\{1,2, \ldots, 96\}$ is a breakpoint at every 15 minutes of the hour, each MW value lasting until next breakpoint (period starting intervals).

The price for the Tertiary Regulation MW value activated by the operator is lower than the price of the Secondary Regulation MW used. Activating the Tertiary Regulation at the right time will reduce the cost of system operation.

Current MW Generation value is the aggregation of the MW output values of all the generators in the Power System at a certain time point. Current MW Generation is a real value situated between minimum power MW value of all the online generators in the system and the total installed MW capacity.

MW system generation has a specific trend over the day ( 24 hours). It has two peaks, the morning peak and the evening peak when MW generation is at its highest (load also) and two off-peaks, the daytime off-peak and the nighttime off-peak when MW generation is at its lowest.

This specific trend is actually generated by the Load which is not flat and usually follows human specific activities. When human activity intensifies the MW Load increases and so does the MW generation.

Current Generation is scheduled a priori and anticipated by the Load Forecast and the Scheduled MW Generation.

$$
G(t)=\operatorname{LoadCurve}(t)=C, t \in \mathbb{R}, \sum P \min \leq C \leq \sum P \max
$$

Where:

- LoadCurve defines the generic trend of the load during 24 hours

- $C$ is a real value on the LoadCurve specific trend limited by the minimum MW power off all online units in the system and total installed MW capacity.

The Schedules MW Generation value is represented by the overall system MW generation values on each representative time interval (Singh, 2014) committed on the Market Platform and programmed to be implemented the next day.

On the Market Platform the demand meets the offer so the Scheduled MW Generation trend follows the Load Curve.

$$
S(t)=\operatorname{LoadCurve}(t)=C, t \in \mathbb{R}, \text { MARKET }_{\text {Min }} \leq C \leq \text { MARKET }_{\text {Max }}
$$

Where:

- LoadCurve defines the generic trend of the load during 24 hours

- $C$ is a real value on the LoadCurve specific trend

- MARKET $_{\text {Min }}$ is the value of all long term MW settlements on each time interval

- MARKET $T_{\text {Max }}$ is the sum of long term and short term (daily) settlements.

The Scheduled MW Generation values are settled for each 15 minutes, using in (7) $T$ instead $t$, where $T=\{1, \ldots, 96\}$ is a breakpoint at every 15 minutes of the hour, each scheduled MW value lasting until next breakpoint (period starting intervals). 
Rogobete, M.; Pintilie, I. \& Scutaru, V.: A Means of Allocating the MW Requirem...

The Load Forecast MW value is computed for each representative time interval of the day and represents the expected load to occur during that period of time (Khamis, 2011). The forecasted MW value for a certain day and a certain time period is determined based on historical data, weather/temperature prognosis, public holidays, etc.

The MW Load on each time interval is generated by human activities. Intense human activity at a certain time of the day translates into an increased MW Load value. Peaks are generated. Most intense human activity is correlated with the evening peak and then with the morning peak. Load Forecast, Scheduled MW and MW Generation follow the Load Curve trend.

$$
L(t)=\operatorname{LoadCurve}(t)=C, t \in \mathbb{R}, M_{\text {EXPECTED }} \leq C \leq M A X_{\text {EXPECTED }}
$$

Where:

- LoadCurve defines the generic trend of the load during 24 hours

- $C$ is a real value on the LoadCurve specific trend

- $M I N_{\text {EXPECTED }}$ is minimum value to be encountered in the scenario of a day with low human activity

- $M A X_{E X P E C T E D}$ is the maximum value to be encountered in a busy day.

The Forecasted MW load is computed for each 15 minutes so function (8) can be expressed with parameter $T$, where $T=\{1, \ldots, 96\}$ is a breakpoint at each 15 minutes, each load MW value lasting until next breakpoint (period starting intervals). Based on the presented inputs we can define the following functions:

Desired Generation change:

$$
r(t)=\left\{\begin{array}{c}
U P(t)=S R U(t)-R(t) \leq 0, R(t)>0, t \in \mathbb{R} \\
D O W N(t)=S R D(t)+R(t) \leq 0, R(t)<0, t \in \mathbb{R}
\end{array}\right.
$$

Where:

- $r(t)$ is the Desired Generation

- $S R U(t)$ is defined in equation (2), $S R D(t)$ is defined in equation (3)

- $R(t)$ is defined in equation (1).

Next Scheduled Generation change (function of $T$ ):

$$
s(T)=\left\{\begin{array}{c}
U P(T)=S(T+1)-S(T)>0 \\
F L A T(t)=S(T+1)-S(T)=0, \\
\operatorname{DOWN}(T)=S(T+1)-S(T)<0
\end{array}\right.
$$

Where $S(t)$ and $S(T)$ are defined in equations (7) and $T=\{1, \ldots, 96\}$ is a breakpoint at each 15 minutes.

Next Load Expected change: 


$$
l(T)=\left\{\begin{array}{c}
U P, L(T+1)-L(T)>0 \\
F L A T, L(T+1)-L(T)=0 \\
D O W N, L(T+1)-L(T)<0
\end{array}\right.
$$

Where

- $L(t)$ and $L(T)$ are defined in equations (8)

- $T=\{1, \ldots, 96\}$ is a breakpoint at each 15 minutes.

Current Generation Tracking function:

$$
g(t)=\left\{\begin{array}{l}
S C H E D U L E, \text { if }|h(t)-S(t)| \leq|h(t)-L(t)|, t \in \mathbb{R} \\
F O R E C A S T, \text { if }|h(t)-S(t)|>|h(t)-L(t)|, t \in \mathbb{R}
\end{array}\right.
$$

Where

$$
h(t)=\int G(t) d t, t \in \text { Current Time Interval }
$$

and

- Current Time Interval is reset every 15 minutes

- $h(t)$ is the mean of the MW Generation over the current time period

- $S(t)$ is defined in equation (7), $L(t)$ is defined in equation (8).

\section{Algorithm/rules description}

The power grid is supervised from a dispatcher console by an operator. For specific situations the operator can do or not the special action in order to add/remove requested power generation.

The following real life scenario has been observed:

- In the eventuality of a high $A C E$ value, due to various network events, a high Regulation Demand value is computed. In the current time interval the value of the Regulation Demand may exceed the Secondary Reserve MW Up or Down value. This event is considered to be persistent such that the $A C E$ value and the Regulation Demand value keep a particular offset in one direction (up or down) during the current time interval. Automatic Generation Control is at the Up or Down limit and incapable to fully regulate the $A C E$. We need to secure the full functionality of the Automatic Generation Control application. The first and most basic procedure is to increase the Up and Down Regulation

- Reserves to cover the excess MW required for raising or lowering generation. This is also the most costly operation we can perform. Activating the Tertiary MW Reserves Up or Down may be a solution, but we consider the next interval MW transition state. By activating Tertiary Regulation we increase/decrease the overall generation on the next time interval. This action itself may be an unwanted destabilizing event (Majstrovic \& Bajs, 2000) for grid power system. 
Rogobete, M.; Pintilie, I. \& Scutaru, V.: A Means of Allocating the MW Requirem...

- Based on the Current Generation MW evolution, the Scheduled MW Generation trend (Costea, 2010) and the Load Forecast trend, we can describe several contexts, when a potentially harmful Regulation Demand MW value occurs. For each particular context an appropriate action can be performed.

All the listed actions below make up the output variable domain.

- In table 1 is presented the logical dependencies between $r(t)$, $s(t)$ and $1(t)$, for Regulation Demand Up case, with the action which should be applied into the power system (using Secondary Reserve UP or Tertiary Reserve UP). The last column describes the numeric status for every case, in order to be drawable.

- The UP Scenario curve decision for every case detected is present in table 2.

- Table 3 describes the logical dependencies between $\mathrm{r}(\mathrm{t}), \mathrm{s}(\mathrm{t})$ and $\mathrm{l}(\mathrm{t})$, for Regulation Demand Down case. The last column describes the numeric status code of DOWN Scenario curve (fig.2) for every case.

\begin{tabular}{|c|c|c|c|c|c|c|c|}
\hline $\begin{array}{l}\text { Crt. } \\
\text { No. }\end{array}$ & $r(t)$ & $s(t)$ & $l(t)$ & $g(t)$ & $\begin{array}{c}\text { Secondary } \\
\text { Reserve UP }\end{array}$ & $\begin{array}{c}\text { Tertiary } \\
\text { Reserve UP }\end{array}$ & $\begin{array}{c}\text { UP Scenario } \\
\text { curve value }\end{array}$ \\
\hline 1 & \multirow[t]{18}{*}{ UP } & \multirow[t]{6}{*}{ UP } & \multirow[t]{2}{*}{$\overline{\mathrm{UP}}$} & SCHEDULE & INCREASE & - & \multirow[t]{2}{*}{100} \\
\hline 2 & & & & FORECAST & INCREASE & - & \\
\hline 3 & & & \multirow[t]{2}{*}{ FLAT } & SCHEDULE & INCREASE & - & \multirow[t]{2}{*}{150} \\
\hline 4 & & & & FORECAST & - & - & \\
\hline 5 & & & \multirow[t]{2}{*}{ DOWN } & SCHEDULE & INCREASE & - & \multirow[t]{2}{*}{150} \\
\hline 6 & & & & FORECAST & - & - & \\
\hline 7 & & \multirow[t]{6}{*}{ FLAT } & \multirow[t]{2}{*}{ UP } & SCHEDULE & INCREASE & - & \multirow[t]{2}{*}{250} \\
\hline 8 & & & & FORECAST & - & ACTIVATE & \\
\hline 9 & & & \multirow[t]{2}{*}{ FLAT } & SCHEDULE & - & ACTIVATE & \multirow[t]{2}{*}{300} \\
\hline 10 & & & & FORECAST & - & ACTIVATE & \\
\hline 11 & & & \multirow[t]{2}{*}{ DOWN } & SCHEDULE & INCREASE & - & \multirow[t]{2}{*}{150} \\
\hline 12 & & & & FORECAST & - & - & \\
\hline 13 & & \multirow[t]{6}{*}{ DOWN } & \multirow[t]{2}{*}{ UP } & SCHEDULE & INCREASE & - & \multirow[t]{2}{*}{250} \\
\hline 14 & & & & FORECAST & - & ACTIVATE & \\
\hline 15 & & & \multirow[t]{2}{*}{ FLAT } & SCHEDULE & INCREASE & - & \multirow[t]{2}{*}{250} \\
\hline 16 & & & & FORECAST & - & ACTIVATE & \\
\hline 17 & & & \multirow[t]{2}{*}{ DOWN } & SCHEDULE & - & ACTIVATE & \multirow[t]{2}{*}{350} \\
\hline 18 & & & & FORECAST & INCREASE & - & \\
\hline
\end{tabular}

Tab. 1. Scenario analysis for Regulation Demand Up

\begin{tabular}{|c|l|l|l|}
\hline $\begin{array}{c}\text { Crt. } \\
\text { No. }\end{array}$ & $\begin{array}{c}\text { Higher } \\
\text { Accuracy } \\
\text { for: }\end{array}$ & \multicolumn{1}{|c|}{ Observations } & $\begin{array}{c}\text { Sufficient action to } \\
\text { perform on the following } \\
\text { reserve: }\end{array}$ \\
\hline 1 & SCHEDULE & Generation will rise and Load will likely follow. & Secondary Reserve Up \\
\hline 2 & FORECAST & $\begin{array}{l}\text { Load will rise and Generation will not follow } \\
\text { correspondingly. }\end{array}$ & Secondary Reserve Up \\
\hline 3 & SCHEDULE & Generation will rise and Load will likely follow. & Secondary Reserve Up \\
\hline 4 & FORECAST & $\begin{array}{l}\text { Load will likely not change but Generation will } \\
\text { rise. }\end{array}$ & $\begin{array}{l}\text { Wait until transition to the } \\
\text { next period starts }\end{array}$ \\
\hline 5 & SCHEDULE & $\begin{array}{l}\text { Generation will rise and Load will likely follow. } \\
\text { Secondary Reserve Up }\end{array}$ \\
\hline 6 & FORECAST & $\begin{array}{l}\text { Load will likely decrease but Generation will } \\
\text { rise. }\end{array}$ & $\begin{array}{l}\text { Wait until transition to the } \\
\text { next period starts }\end{array}$ \\
\hline
\end{tabular}




\begin{tabular}{|c|c|c|c|}
\hline 7 & SCHEDULE & $\begin{array}{l}\text { Generation will stay the same and load will } \\
\text { likely rise }\end{array}$ & Secondary Reserve Up \\
\hline 8 & FORECAST & $\begin{array}{l}\text { Load will most likely rise but generation will } \\
\text { stay unchanged }\end{array}$ & Tertiary Reserves Up \\
\hline 9 & SCHEDULE & $\begin{array}{l}\text { Generation will stay unchanged and load most } \\
\text { likely will follow }\end{array}$ & Tertiary Reserves Up \\
\hline 10 & FORECAST & $\begin{array}{l}\text { Load will not likely stay unchanged and } \\
\text { generation also }\end{array}$ & Tertiary Reserves Up \\
\hline 11 & SCHEDULE & $\begin{array}{l}\text { Generation will stay unchanged but load might } \\
\text { go down }\end{array}$ & Secondary Reserves Up \\
\hline 12 & FORECAST & $\begin{array}{l}\text { Load will probably go down and generation will } \\
\text { stay unchanged }\end{array}$ & $\begin{array}{l}\text { Wait until transition to the } \\
\text { next period starts }\end{array}$ \\
\hline 13 & SCHEDULE & Generation will go down and load might rise & Secondary Reserves Up \\
\hline 14 & FORECAST & $\begin{array}{l}\text { Load most likely will rise while generation will } \\
\text { go down }\end{array}$ & Tertiary Reserve Up \\
\hline 15 & SCHEDULE & $\begin{array}{l}\text { Generation will go down while load might stay } \\
\text { unchanged }\end{array}$ & Secondary Reserves up \\
\hline 16 & FORECAST & $\begin{array}{l}\text { Load is most likely to stay unchanged while } \\
\text { generation will go down }\end{array}$ & Tertiary Reserves Up \\
\hline 17 & SCHEDULE & Generation will go down and load might follow & Tertiary Reserves Up \\
\hline 18 & FORECAST & $\begin{array}{l}\text { Load most likely will go down and generation } \\
\text { will go down also }\end{array}$ & Secondary Reserves Up \\
\hline
\end{tabular}

Tab. 2. Specific operation for every system state, for Regulation Demand Up

\begin{tabular}{|c|c|c|c|c|c|c|c|}
\hline $\begin{array}{l}\text { Crt. } \\
\text { No. }\end{array}$ & $r(t)$ & $s(t)$ & $l(t)$ & $g(t)$ & $\begin{array}{c}\text { Secondary } \\
\text { Reserve } \\
\text { DOWN }\end{array}$ & $\begin{array}{c}\text { Tertiary } \\
\text { Reserve } \\
\text { Down }\end{array}$ & $\begin{array}{c}\text { DOWN } \\
\text { Scenario } \\
\text { curve value }\end{array}$ \\
\hline 1 & \multirow[t]{18}{*}{ DOWN } & \multirow[t]{6}{*}{ 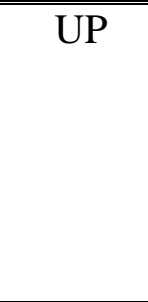 } & \multirow[t]{2}{*}{$\overline{\mathrm{UP}}$} & SCHEDULE & - & ACTIVATE & \multirow[t]{2}{*}{-100} \\
\hline 2 & & & & FORECAST & INCREASE & - & \\
\hline 3 & & & \multirow[t]{2}{*}{ FLAT } & SCHEDULE & INCREASE & - & \multirow[t]{2}{*}{-150} \\
\hline 4 & & & & FORECAST & & ACTIVATE & \\
\hline 5 & & & \multirow[t]{2}{*}{ DOWN } & SCHEDULE & INCREASE & - & \multirow[t]{2}{*}{-150} \\
\hline 6 & & & & FORECAST & - & ACTIVATE & \\
\hline 7 & & \multirow[t]{6}{*}{ FLAT } & \multirow[t]{2}{*}{ UP } & SCHEDULE & INCREASE & - & \multirow[t]{2}{*}{-200} \\
\hline 8 & & & & FORECAST & - & - & \\
\hline 9 & & & \multirow[t]{2}{*}{ FLAT } & SCHEDULE & - & ACTIVATE & \multirow[t]{2}{*}{-300} \\
\hline 10 & & & & FORECAST & - & ACTIVATE & \\
\hline 11 & & & \multirow[t]{2}{*}{ DOWN } & SCHEDULE & INCREASE & - & \multirow[t]{2}{*}{-150} \\
\hline 12 & & & & FORECAST & - & ACTIVATE & \\
\hline 13 & & \multirow[t]{6}{*}{ DOWN } & \multirow[t]{2}{*}{ UP } & SCHEDULE & INCREASE & - & \multirow[t]{2}{*}{-200} \\
\hline 14 & & & & FORECAST & - & - & \\
\hline 15 & & & \multirow[t]{2}{*}{ FLAT } & SCHEDULE & INCREASE & - & \multirow[t]{2}{*}{-200} \\
\hline 16 & & & & FORECAST & - & - & \\
\hline 17 & & & \multirow[t]{2}{*}{ DOWN } & SCHEDULE & INCREASE & - & \multirow[t]{2}{*}{-250} \\
\hline 18 & & & & FORECAST & INCREASE & - & \\
\hline
\end{tabular}

Tab. 3. Scenario analysis for Regulation Demand Up

While the fuzzy blocks were used successfully in adaptive neuro-fuzzy inference for distributed power flow control (Rao \& Kumar, 2014), this work simplified the 
Rogobete, M.; Pintilie, I. \& Scutaru, V.: A Means of Allocating the MW Requirem...

simulation using four inference fuzzy blocks (Bonato, 2013), (as there are four input vectors) with 9 rules for every scenario (tables 1 and 3 ).

\begin{tabular}{|c|c|c|c|}
\hline $\begin{array}{l}\text { Crt. } \\
\text { No. }\end{array}$ & $\begin{array}{l}\text { Higher } \\
\text { Accuracy } \\
\text { for: }\end{array}$ & Observations & $\begin{array}{c}\text { Sufficient action to } \\
\text { perform on the following } \\
\text { reserve: }\end{array}$ \\
\hline 1 & SCHEDULE & $\begin{array}{l}\text { Generation will rise and load will probably } \\
\text { follow. }\end{array}$ & Tertiary Reserves Down \\
\hline 2 & FORECAST & $\begin{array}{l}\text { Load will most likely rise and generation will } \\
\text { follow. }\end{array}$ & $\begin{array}{l}\text { Secondary Reserves } \\
\text { Down }\end{array}$ \\
\hline 3 & SCHEDULE & $\begin{array}{l}\text { Generation will rise and load will probably stay } \\
\text { the same. }\end{array}$ & $\begin{array}{l}\text { Secondary } \\
\text { Down }\end{array}$ \\
\hline 4 & FORECAST & $\begin{array}{l}\text { Load will probably stay unchanged while } \\
\text { generation will rise. }\end{array}$ & Tertiary Reserves Down \\
\hline 5 & SCHEDULE & Generation will rise and load might go down. & Secondary Reserve Down \\
\hline 6 & FORECAST & $\begin{array}{l}\text { Load will likely decrease but Regulation will } \\
\text { rise. }\end{array}$ & Tertiary Reserve Down \\
\hline 7 & SCHEDULE & $\begin{array}{l}\text { Generation stays unchanged while load might } \\
\text { increase. }\end{array}$ & Secondary Reserve Down \\
\hline 8 & FORECAST & $\begin{array}{l}\text { Load will probably rise while generation } \\
\text { remains unchanged }\end{array}$ & $\begin{array}{l}\text { Wait until transition to } \\
\text { next period starts }\end{array}$ \\
\hline 9 & SCHEDULE & $\begin{array}{l}\text { Generation will stay unchanged and the load } \\
\text { most likely too }\end{array}$ & Tertiary Reserve Down \\
\hline 10 & FORECAST & $\begin{array}{l}\text { Load will probably stay unchanged and } \\
\text { generation also. }\end{array}$ & Tertiary Reserve Down \\
\hline 11 & SCHEDULE & $\begin{array}{l}\text { Generation will decrease and load will probably } \\
\text { go up. }\end{array}$ & Secondary Reserve Down \\
\hline 12 & FORECAST & $\begin{array}{l}\text { Load will most probably decrease and } \\
\text { generation will remain the same }\end{array}$ & Tertiary Reserve Down \\
\hline 13 & SCHEDULE & Generation will go down while load might go up & Secondary Reserve Down \\
\hline 14 & FORECAST & $\begin{array}{l}\text { Load is most likely to go up while generation } \\
\text { goes down }\end{array}$ & $\begin{array}{l}\text { Wait until transition to } \\
\text { next period starts }\end{array}$ \\
\hline 15 & SCHEDULE & $\begin{array}{l}\text { Generation will go down while load will } \\
\text { probably stay unchanged }\end{array}$ & Secondary Reserve Down \\
\hline 16 & FORECAST & $\begin{array}{l}\text { Load is most likely to stay unchanged while } \\
\text { generation will go down }\end{array}$ & $\begin{array}{l}\text { Wait until transition to } \\
\text { next period starts }\end{array}$ \\
\hline 17 & SCHEDULE & $\begin{array}{l}\text { Generation will go down and load might follow } \\
\text { the trend }\end{array}$ & Secondary Reserve Down \\
\hline 18 & FORECAST & $\begin{array}{l}\text { Load is most likely to go down and so will the } \\
\text { generation }\end{array}$ & Secondary Reserve Down \\
\hline
\end{tabular}

Tab. 4. Specific operation for every system state, for Regulation Demand Down

\section{Analysis of the results}

In figure 1 there are all the main inputs for fuzzy system. Off course that Scheduled Generation, s(t), Load Forecast, $\mathrm{l}(\mathrm{t})$ and Current Generation , $\mathrm{g}(\mathrm{t})$ are preprocessed together with there limits and then applied for every inference fuzzy module. 
The results of the fuzzy analysis are represented into figure 2 , with the values for UP Scenario and DOWN Scenario curves, conforming to table 1, respectively table 3.

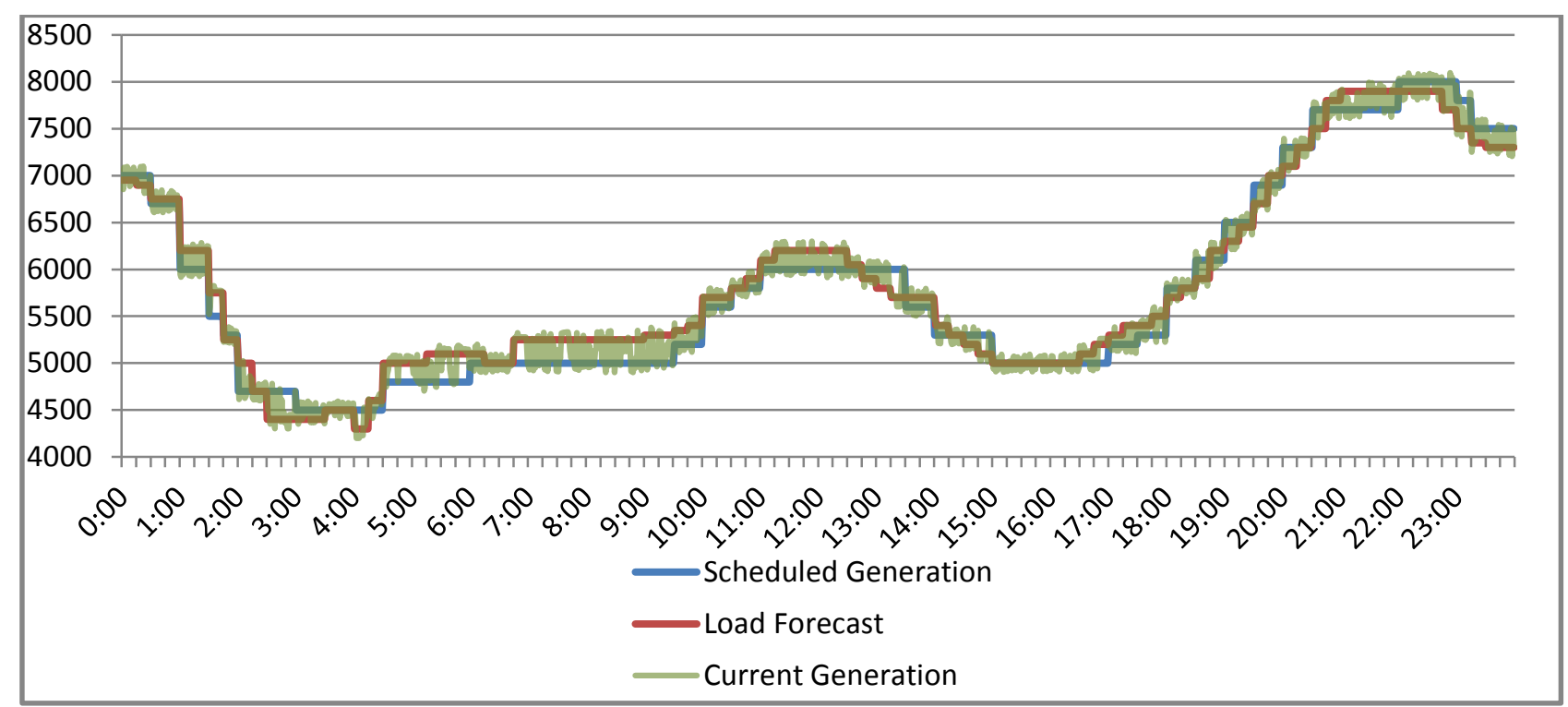

Fig. 1. Graphical representation for Scheduled Generation, $s(t)$, Load Forecast, $l(t)$ and Current Generation, $g(t)$

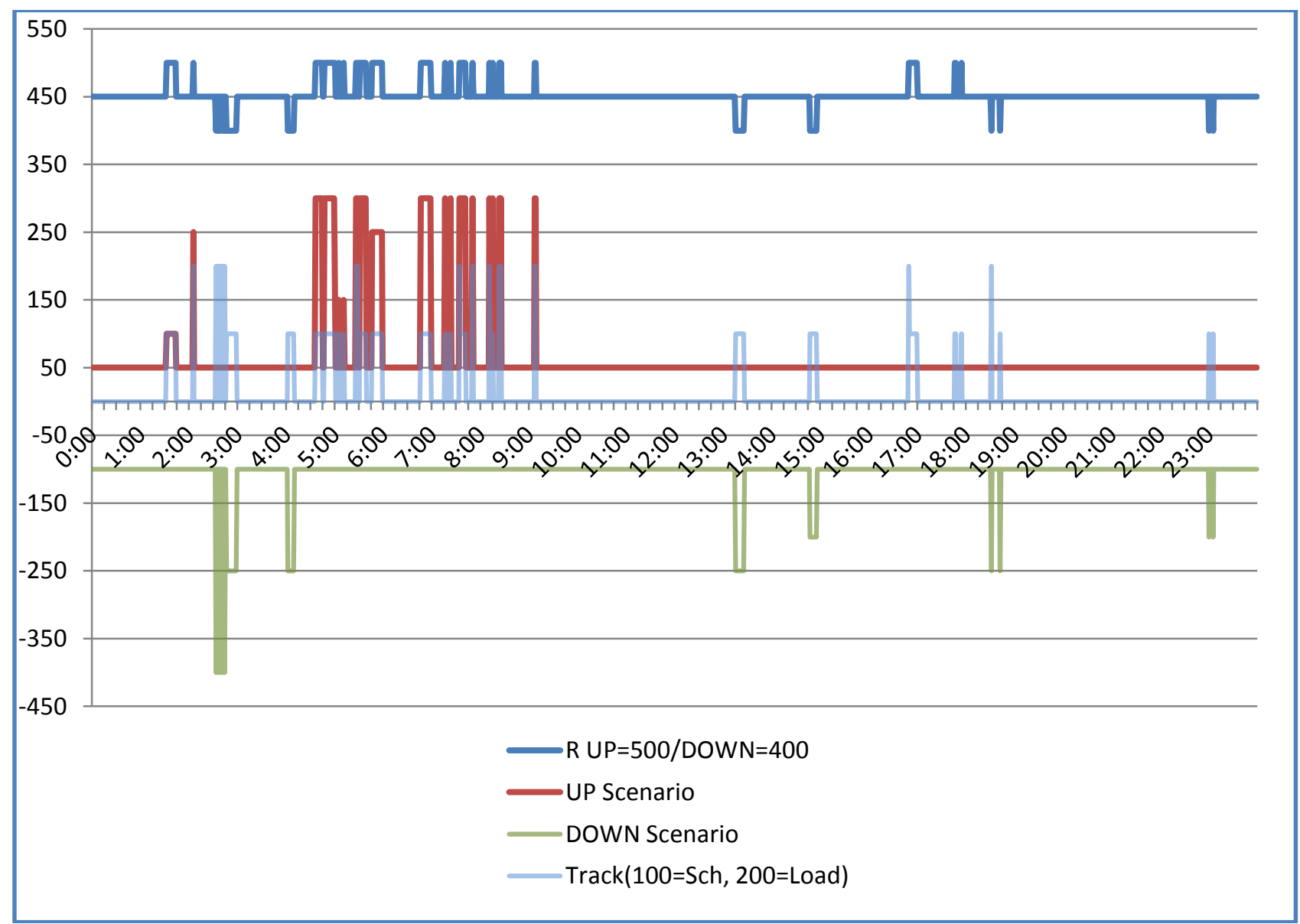

Fig. 2. Intermediary and finally results of the inference fuzzy

In figure 2 are graphically represented the intermediary and finally results of the inference fuzzy system (OUTPUTS: UP Scenario curve and DOWN Scenario curve) 
Rogobete, M.; Pintilie, I. \& Scutaru, V.: A Means of Allocating the MW Requirem...

where the values of the system status are defined in table 1 (for UP) and table 3 (for DOWN).

\section{Conclusions}

The presented application assists the human decision in order to assure the best choice for the power system operator in the most difficult cases.

As the analysis has a prognosis and trends segment, we have used inference fuzzy system modules of Matlab with preprocessed inputs vectors and several rules (table 1 and table 3), resulting a model able to choose specific system state.

The system behavior is not disturbed of any kind of noisy as the human operator can be, but more of this, it does the best choice when the defined rules are satisfied. The figure 2 shows graphically the possible decision level, passed for supervising to the dispatcher operator.

The capabilities of decision an analysis are extremely large and very flexible; therefore a large pallet of rules and prognosis/trends methods can be applied, specific for different power system characteristics.

\section{References}

Bonato, J(2013) Methods of Artificial Intelligence - Fuzzy Logic, Chapter 51 in DAAAM International Scientific Book 2013, pp. 849-856, B. Katalinic \& Z. Tekic (Eds.), Published by DAAAM International, ISBN 978-3-901509-94-0, ISSN 17269687, Vienna, Austria

Costea, C., on distributed model predictive control for load frequency problem, 13th Daaam International Symposium - Carpathian Journal of Electrical Engineering, Volume 4, Number 1, 2010, ISSN 1843-7583, Cluj-Napoca, Romania

Eremia,M.; Simon, P. \& Petricica, D., Some aspects of hierarchical voltage-reactive power control ,Power Engineering Society Summer Meeting, Vol. 2, pp. 872-880, July 2001, IEEE, Vancouver, Canada

Khamis, M.; Baharudin, Z. ; Hamid, N.H., Short term load forecasting for small scale power system using fuzzy logic, IEEE Explore Conference Kuala Lumpur, Malaysia, April 2011 , Published by IEEE, ISBN 978-1-4577-0003-3

Majstrovic, M.; Bajs, D. \& Majstrovic, G., influence of power system stabilizer on the transient stability, international daaam symposium "Intelligent Manufacturing \& Automation: Man - Machine - Nature",October 2000

Rao B.;Kumar V. \& Ram S., An Adaptive Neuro-Fuzzy Inference Distributed Power Flow Controller (DPFC) in Multi-Machine Power Systems, International Journal of Power Electronics and Drive System, Vol.5, No.2, October 2014, pp. 230 236, ISSN 2088-8694

Singh, P.; Titare, L.; Arya, L., MW-rescheduling based on eigen sensitivities to enhance voltage security using DE, Power and Energy Systems Conference: Towards Sustainable Energy, Bangalore, March 2014, IEEE ISBN 978-1-4799-3420-1 